\title{
Global and regional right ventricular function after acute myocardial infarction: dependence upon site of left ventricular infarction
}

\author{
JOHN L CAPLIN, DUNCAN S DYMOND, WILLIAM D FLATMAN, * \\ ROWORTH A J SPURRELL \\ From the Departments of Cardiology and ${ }^{\star} N u c l e a r$ Medicine, St Bartholomew's Hospital, London
}

\begin{abstract}
SUMMARY The relation of global and regional right and left ventricular function during the acute phase after a first myocardial infarction was assessed by first pass radionuclide angiography in 20 patients (10 after anterior and 10 after inferior myocardial infarction). The right ventricular ejection fraction did not differ significantly between the groups, but left ventricular ejection fraction was significantly depressed after anterior myocardial infarction. There was evidence of right ventricular dilatation and impaired transit in the group with inferior infarction. Five patients with anterior infarction and six with inferior infarction had abnormal right ventricular ejection fractions. Right ventricular wall motion abnormalities affected the septal wall in the group with anterior infarction and the free wall in the group with inferior infarction. The relation between right and left ventricular ejection fractions was markedly different in the two groups. In the group with anterior infarction there was a significant linear relation between right and left ventricular ejection fraction, whereas in the group with inferior infarction there was not.

Thus right ventricular dysfunction commonly occurs after both anterior and inferior myocardial infarction. Right and left ventricular impairment are related after anterior myocardial infarction, but are independent after inferior myocardial infarction. Finally, the different effects of anterior and inferior myocardial infarction on right ventricular function may be explained by differences in septal and free wall involvement.
\end{abstract}

Right ventricular dysfunction secondary to right ventricular myocardial infarction is now well recognised. ${ }^{1}$ Invasive haemodynamic monitoring allows primary abnormalities of right ventricular function to be distinguished from those that are secondary to left ventricular dysfunction. ${ }^{2}$ The right ventricular free wall is exclusively supplied by the right coronary artery, ${ }^{3}$ and therefore most studies of right ventricular function after myocardial infarction have concentrated on patients with inferior infarction.

Rigo et al reported dilatation of the right ventricle after inferior infarction. ${ }^{4}$ Since then there have been conflicting reports, with some investigators finding right ventricular dysfunction after inferior

Requests for reprints to Dr John L Caplin, Department of Cardiology, Southampton General Hospital, Tremona Road, Southampton SO9 4XY.

Accepted for publication 25 February 1987 infarction but not after anterior infarction, ${ }^{56}$ while others have found it in both groups. ${ }^{7}$

Since not only the right ventricular free wall but also the interventricular septum contribute to right ventricular contraction, ${ }^{8}$ septal involvement in anterior infarction might be expected to cause some degree of right ventricular dysfunction. To assess the extent of right ventricular dysfunction after myocardial infarction and its relation to the site of left ventricular infarction we assessed global and regional right and left ventricular function in a population of patients admitted during the acute phase of their first myocardial infarction.

\section{Patients and methods}

PATIENTS

We studied 20 patients (19 men; mean (SD) age 53.8 (8.9), range 35-65 years) (table 1 ). They had no 
Table 1 Clinical details and right and left ventricular indices in 20 patients with acute anterior or inferior infarction

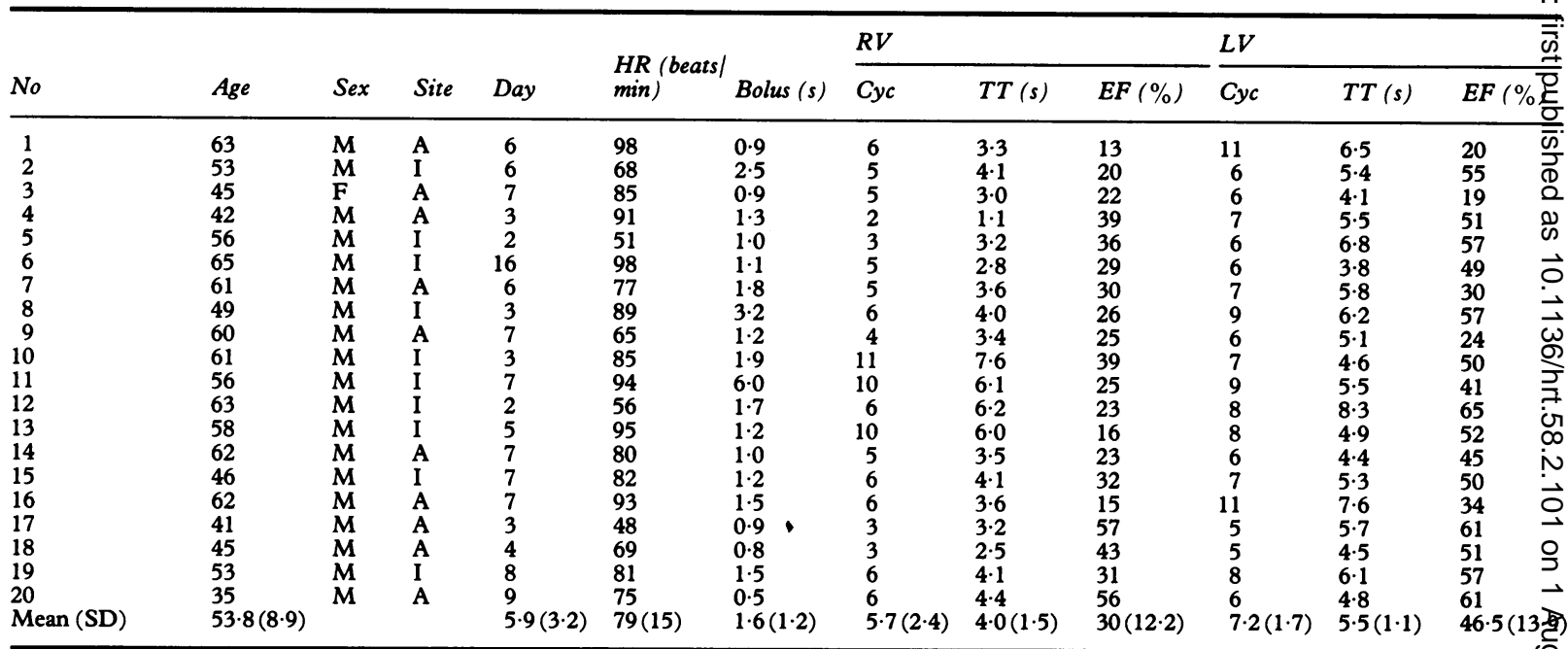

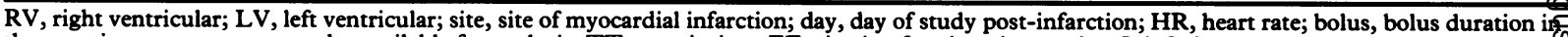
the superior vena cava; cyc, cycles available for analysis; TT, transit time; EF, ejection fraction; A, anterior; I, inferior.

clinical or electrocardiographic evidence of a previous myocardial infarction. All presented with typical ischaemic chest pain, all developed electrocardiographic changes characteristic of a transmural myocardial infarction (ST segment elevation, $T$ wave inversion, and $Q$ waves), and all had diagnostic serial changes in serum cardiac enzymes. The infarction was defined as inferior if the electrocardiographic changes developed in leads II, III, and $\mathrm{aVF}$, and as anterior if the changes occurred in any two consecutive leads from leads V1-V6. Patients were not included if the site of infarction could not be defined by this system. Patients were studied in the acute phase of infarction as soon as it was considered safe for them to be moved to the nuclear cardiology laboratory.

\section{RADIONUCLIDE ANGIOGRAPHY}

First pass radionuclide angiography was performed with a multicrystal gamma camera (Baird System77 ) in the $30^{\circ}$ right anterior oblique projection in supine resting patients as previously described. ${ }^{9}$ An 18 gauge cannula was inserted into a medial antecubital fossa vein and $660 \mathrm{MBq}$ of technetium-99m was injected for each study by rapid saline flush. Data were acquired for $30 \mathrm{~s}$ at $30 \mathrm{~ms}$ framing intervals.

DATA ANALYSIS

Global right ventricular function

Radionuclide bolus duration was assessed from time-activity curves derived from a region of interest over the superior vena cava. ${ }^{10}$ Right ventricular ejection fraction was calculated by a previously described method. ${ }^{11}$

Heart rate, right ventricular transit time (defined as the duration of activity in the right ventricle), and right ventricular cycles were derived from the right ventricular time-activity curve, and the planar right ventricular area was derived from the right ventricular region of interest. This measure was included to allow comparison with the study of Rigo $\mathrm{et}_{\mathrm{al}}{ }^{4}$ who used planar right ventricular area as an index of right ventricular dilatation. ${ }^{4}$

\section{Global left ventricular function}

Left ventricular ejection fraction and functional images were derived from high frequency timeactivity curves by a standard software program as previously described. ${ }^{9}$

\section{Regional left and right ventricular function}

Regional wall motion was assessed from countbased regional ejection fraction images. These were derived from end systolic and end diastolic images, and showed the proportionate change in counts and hence the volume within each part of the ventricle. The left ventricular border was visually divided into three equal segments: anterior, apical, and inferior. A segment was deemed to be abnormal if more than half of it showed a regional ejection fraction of $<50 \% .{ }^{12}$ The right ventricle was arbitrarily divided into two equal segments. The inferior border from the tricuspid valve plane to the apex was defined as 
Table 2 Comparison of the results in patients with anterior and inferior myocardial infarctions. Results expressed as mean (SD)

\begin{tabular}{|c|c|c|c|}
\hline & $\begin{array}{l}\text { Anterior } \\
(n=10)\end{array}$ & $\begin{array}{l}\text { Inferior } \\
(n=10)\end{array}$ & $p$ value \\
\hline $\begin{array}{l}\text { Age (years) } \\
\text { Day } \\
\text { Heart rate (beats/min) } \\
\text { Bolus (s) } \\
\text { RV area }\left(\mathrm{cm}^{2}\right) \\
\text { RV cycles } \\
\text { RV TT }(\mathbf{s}) \\
\text { LV cycles } \\
\text { LV TT }(\mathrm{s}) \\
\text { RVEF }(\%) \\
\text { LVEF }(\%)\end{array}$ & $\begin{array}{c}51 \cdot 6(10 \cdot 9) \\
5 \cdot 9(2 \cdot 0) \\
78 \cdot 1(14 \cdot 9) \\
1 \cdot 1(0 \cdot 4) \\
38 \cdot 4(12 \cdot 2) \\
4 \cdot 5(1 \cdot 4) \\
3 \cdot 2(0 \cdot 9) \\
7 \cdot 0(2 \cdot 2) \\
5 \cdot 4(1 \cdot 1) \\
32 \cdot 3(15 \cdot 8) \\
39 \cdot 6(16 \cdot 3)\end{array}$ & $\begin{array}{c}56 \cdot 0(6 \cdot 0) \\
5 \cdot 9(4 \cdot 2) \\
80 \cdot 0(16 \cdot 4) \\
2 \cdot 1(1 \cdot 5) \\
50 \cdot 5(5 \cdot 7) \\
6 \cdot 8(2 \cdot 6) \\
4 \cdot 8(1 \cdot 5) \\
7 \cdot 4(1 \cdot 2) \\
5 \cdot 7(1 \cdot 3) \\
27 \cdot 2(7 \cdot 1) \\
53 \cdot 3(6 \cdot 4)\end{array}$ & $\begin{array}{l}\text { NS } \\
\text { NS } \\
\text { NS } \\
\text { NS } \\
<0.05 \\
<0.05 \\
<0.01 \\
\text { NS } \\
\text { NS } \\
\text { NS } \\
<0.05\end{array}$ \\
\hline
\end{tabular}

the "free wall" segment and the anterior border from the apex to pulmonary outflow tract was defined as the "septal" segment. ${ }^{8}$

\section{Statistical analysis}

The results are expressed as mean (SD). Results within a group were compared by paired $t$ tests and results between groups by unpaired $t$ tests. Correlation coefficients ( $r$ ) were derived by a standard software program.

\section{Results}

\section{ALL PATIENTS}

Table 1 shows results in all patients. The patients were studied $5.9(3.2)$ days (range 2-16) after infarction. The number of right ventricular cycles $(5 \cdot 7(2 \cdot 4))$ that were available was significantly less than for the number of left ventricular cycles $(7 \cdot 2(1.7))(p<0.01)$. The transit time of the right ventricle $(4.0(1.5) \mathrm{s})$ was significantly shorter than

Table 3 Right and left ventricular regional wall motion abnormalities after anterior and inferior myocardial infarction

Anterior $(n=10)$ Inferior $(n=10)$

\begin{tabular}{lll}
\hline Right ventricle: & & \\
Normal & 6 & 5 \\
Septal & 3 & 0 \\
Free wall & 0 & 4 \\
Diffuse & 1 & 1 \\
& & \\
Left ventricle: & 1 & 3 \\
$\quad$ Normal & 2 & 0 \\
Anterior & 5 & 0 \\
Anteroapical & 1 & 0 \\
Apical & 0 & 5 \\
Inferior & 0 & 2 \\
Inferoapical & 1 & 0 \\
Diffuse & & \\
\hline
\end{tabular}

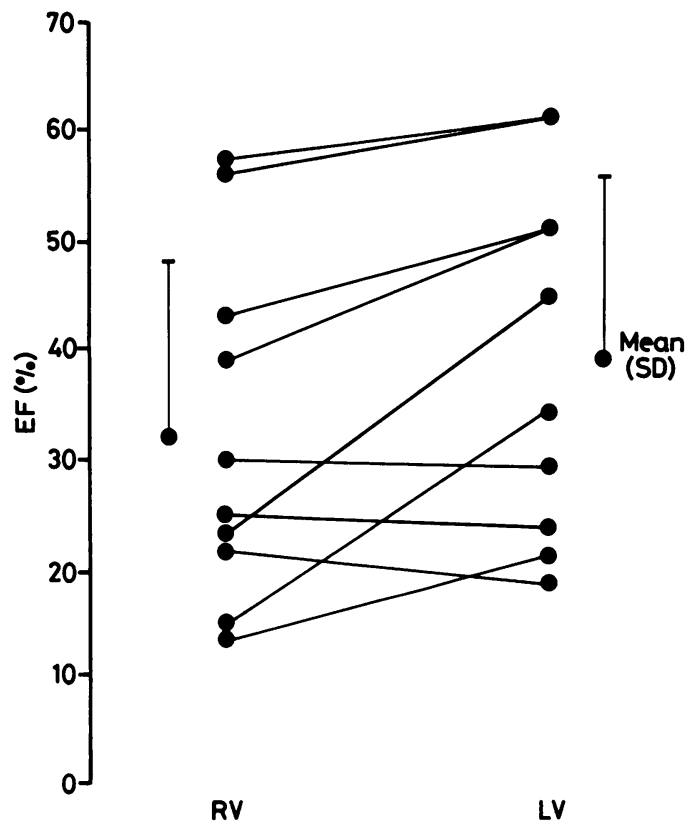

Fig 1 Right ( $R V)$ and left ( $L V)$ ventricular ejection fractions $(E F \%)$ in the ten patients with anterior myocardial infarction. The values for each patient are joined by a solid line. Note the wide range of right and left ventricular ejection fractions.

that of the left $(5.5(1 \cdot 1) \mathrm{s})(\mathrm{p}<0.001)$. The right ventricular ejection fraction was $30(12 \cdot 2) \%$ (range 13-56) and the left ventricular ejection fraction was $46.5(13.9) \%$ (range 19-65) $(p<0.001)$. Eleven of 20 patients had a right ventricular ejection fraction of $<30 \%$. This represents our lower limit of normal derived from 21 normal volunteers without clinical or electrocardiographic evidence of heart disease. ${ }^{13}$ Eight of the 20 patients had an abnormal left ventricular ejection fraction $(<50 \%)$.

\section{ANTERIOR MYOCARDIAL INFARCTION}

Table 2 shows the results for the global variables of ventricular function and table 3 shows regional function. Right ventricular area was $38 \cdot 4(12 \cdot 2) \mathrm{cm}^{2}$. There were $4.5(1.4)$ cycles available for analysis of the right ventricle and $7 \cdot 0(2 \cdot 2)$ for the left ventricle $(p<0.01)$. Transit time was $3.2(0.9)$ s for the right ventricle and $5 \cdot 4(1 \cdot 1) \mathrm{s}$ for the left ventricle $(\mathrm{p}<0.001)$. Right ventricular ejection fraction was $32 \cdot 3(15.8 \%)$ and left ventricular ejection fraction was $39.3(16.3) \%(p<0.05)$. Five of ten patients had abnormal right ventricular ejection fractions and six of ten had abnormal left ventricular ejection fractions. Figure 1 shows the ranges of right and left 


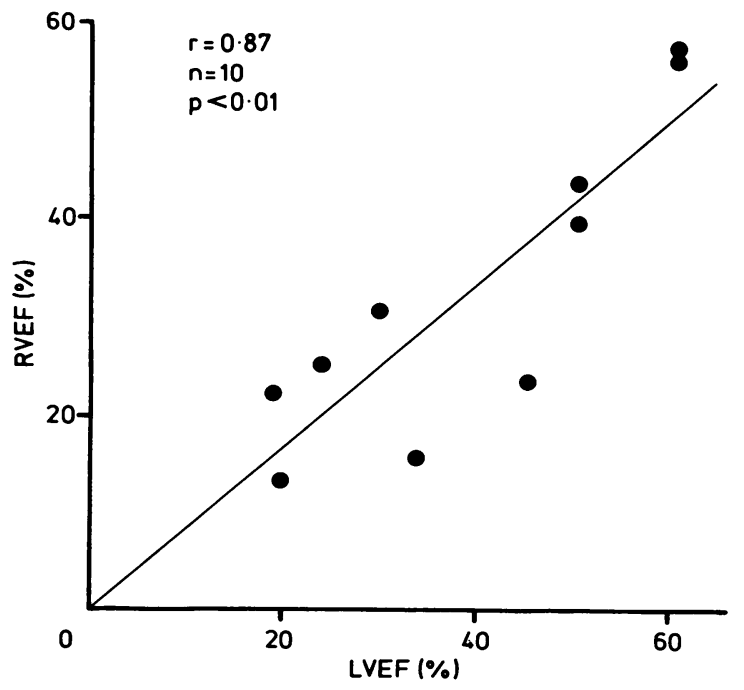

Fig 2 Relation between right and left ventricular ejection fractions in 10 patients after anterior myocardial infarction. The line represents the best fit; the correlation coefficient $(r)$ and corresponding $p$ value are shown.

ventricular ejection fractions in all patients. Figure 2 shows the relation between right and left ventricular ejection fractions. This shows a linear relation $(r=$ $0.87, \mathrm{p}<0.01$ ).

Table 3 lists the regional abnormalities; four of the five patients with abnormal right ventricular ejection fractions had regional right ventricular $\stackrel{\varrho}{\rightleftharpoons}$ abnormalities. Nine patients, three with normal left $c$. ventricular ejection fractions, showed abnormalities $\vec{F}$. of regional left ventricular function. Figure 3 shows $\stackrel{5}{+}$ the images in a patient with a small anterior infarction with normal right and left ventricular $\frac{\overline{-}}{\bar{n}}$ ejection fractions and normal regional wall motion. $\frac{\text { ? }}{-}$ In contrast, fig 4 shows the images in a patient who $\propto$ had impaired right and left ventricular function after $\%$ anterior infarction; this patient had septal right ven- $\vec{O}$ tricular and anterior left ventricular wall motion abnormalities.

\section{INFERIOR MYOCARDIAL INFARCTION}

Tables 2 and 3 show the results in patients with of inferior myocardial infarction. The mean right ventricular area was $50 \cdot 5(5 \cdot 7) \mathrm{cm}^{2}$. There were $6 \cdot 8(2 \cdot 6)$ cycles available for the right ventricle and 7.4(1.2)오 for the left ventricle ( $p, N S)$. Transit time was $ᄋ$ $4.8(1.5)$ s for the right ventricle and $5.7(1.3)$ s for the left ventricle ( $p, N S)$. Right ventricular ejection $\gg$ fraction was $27 \cdot 2(7 \cdot 1) \%$ and left ventricular ejection 0 fraction was $53.3(6.4) \%(p<0.001)$. Six of ten $\stackrel{\odot}{\rightarrow}$ patients had abnormal right ventricular ejection $\vec{P}$

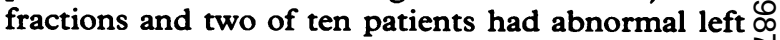
ventricular ejection fractions. Figure 5 shows the ${ }^{-}$ right and left ventricular ejection fractions in all patients. Figure 6 shows the relation between right and left ventricular ejection fraction in this group. In contrast to the anterior infarction group there was no significant relation $(r=-0 \cdot 1)$.

Table 3 lists the regional abnormalities. Five of $\overrightarrow{\vec{A}}$ the six patients with abnormal right ventricular ejec- $\frac{O}{3}$

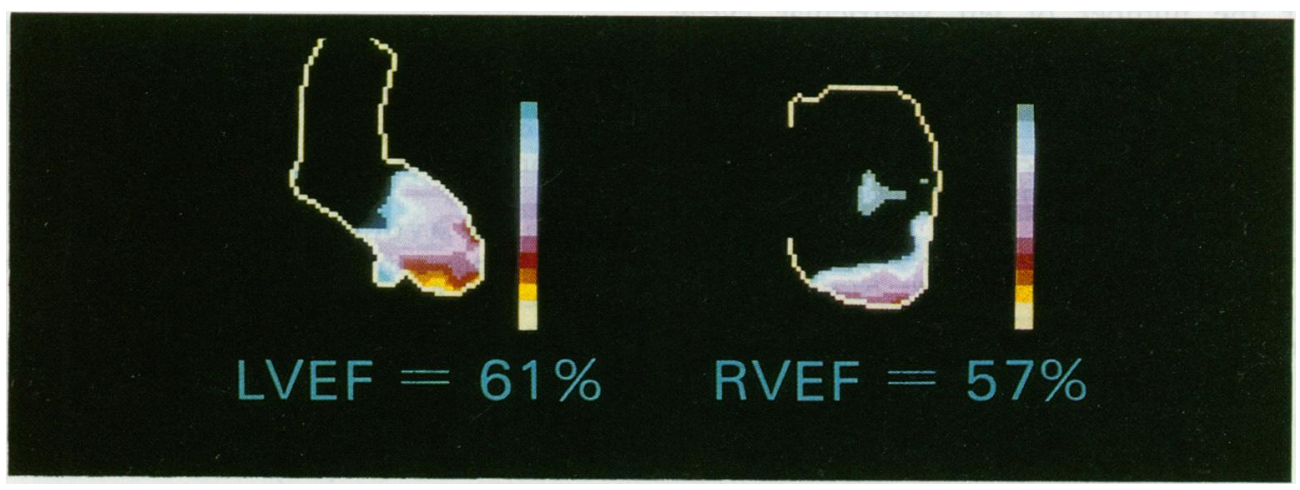

Fig 3 Right and left ventricular regional ejection fraction images in a patient with a small anterior myocardial infarction. The colour scale shows regional ejection from yellow $(100 \%)$; through orange, red, and blue to pale blues, and green; and finally black (0\%). Each point on the scale represents a $6 \cdot 25 \%$ change in regional ejection fraction. In this case the regional images are just within normal limits, although there is a small area of anterior hypokinesis just above the apex of the left ventricle. 


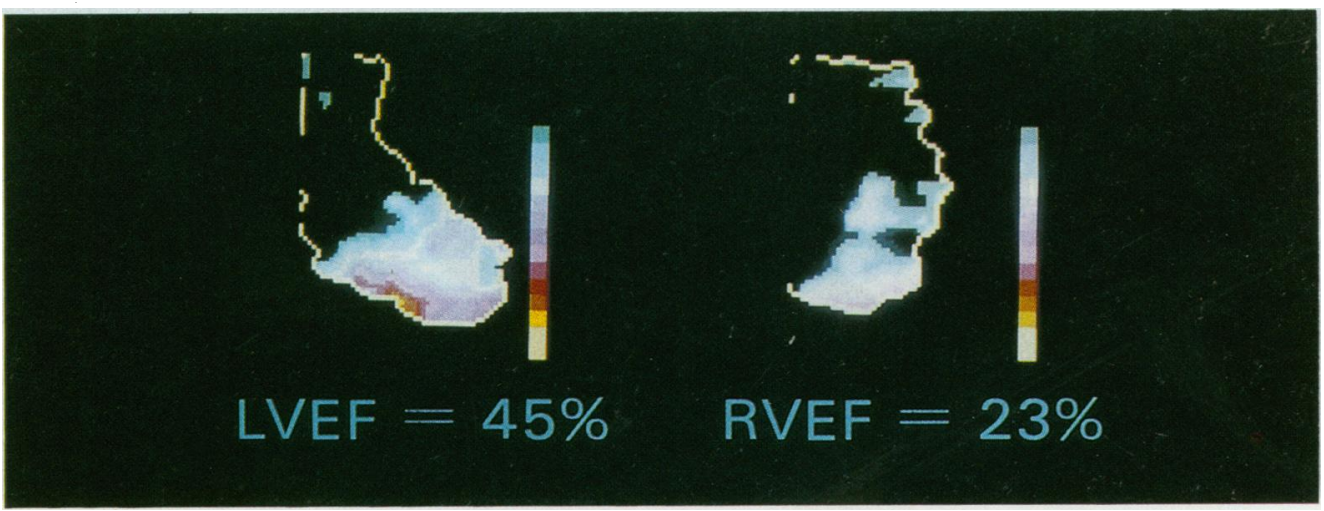

Fig 4 Right and left ventricular regional ejection fraction images in a patient with an anterior myocardial infarction and associated septal right ventricular hypokinesis (right border). See fig 3 for colour scale.

tion fractions had abnormalities of regional function. Seven patients had regional left ventricular abnormalities and two of these also had abnormal left ventricular ejection fractions. Figure 7 shows

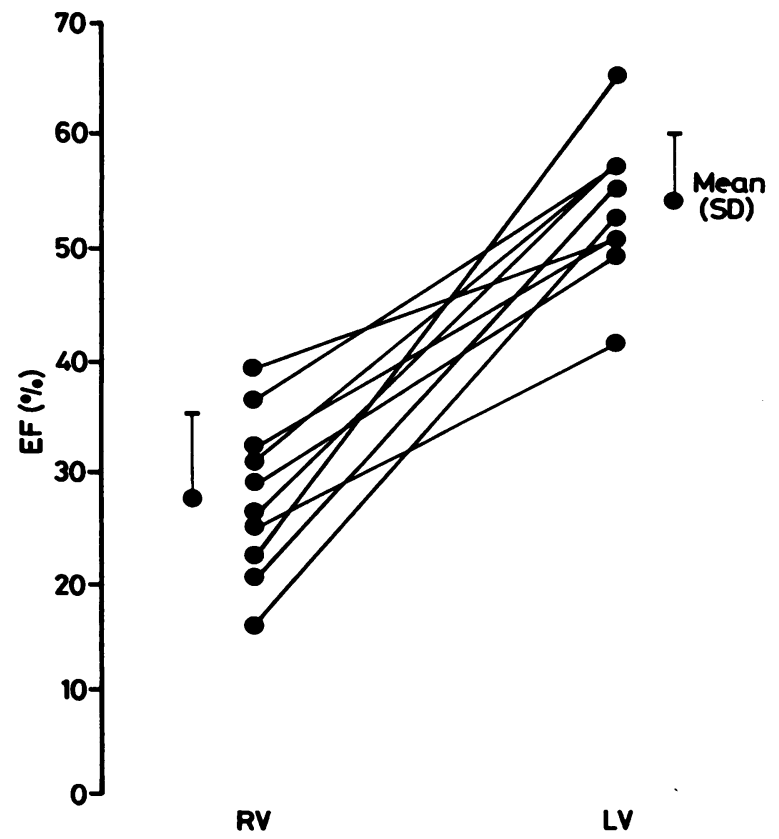

Fig 5 Right and left ventricular ejection fractions in the ten patients with inferior myocardial infarctions. The format is the same as in fig 1. The range of right and left ventricular ejection fractions was much narrower than in the group with anterior myocardial infarction ( fig 1). images in a patient with impaired right and left ventricular function after an inferior infarction. There was a right ventricular free wall abnormality and inferior left ventricular hypokinesis.

COMPARISON BETWEEN ANTERIOR AND INFERIOR MYOCARDIAL INFARCTION

There were no significant differences in age, day of study, heart rate, of radionuclide bolus duration in

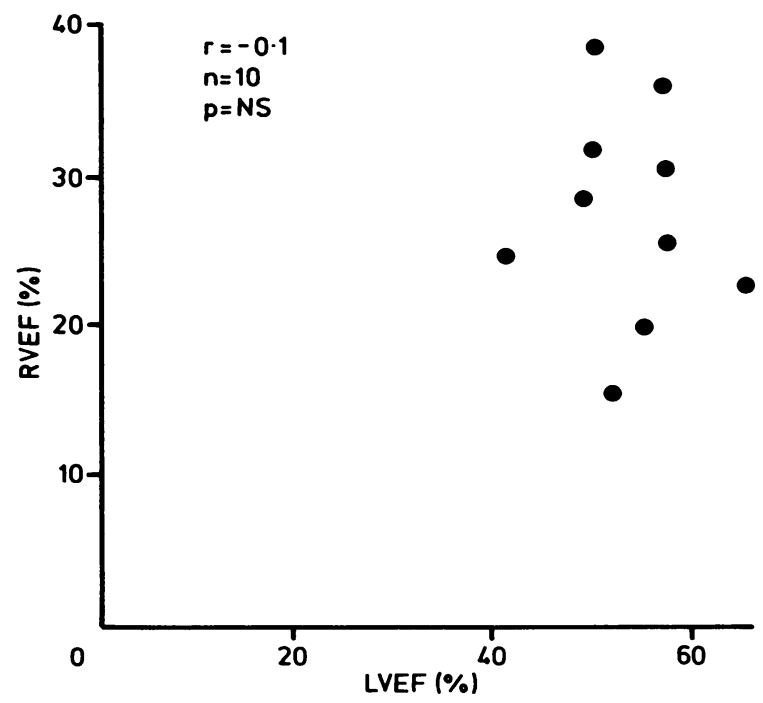

Fig 6 Relation between right and left ventricular function in patients after inferior myocardial infarction. 


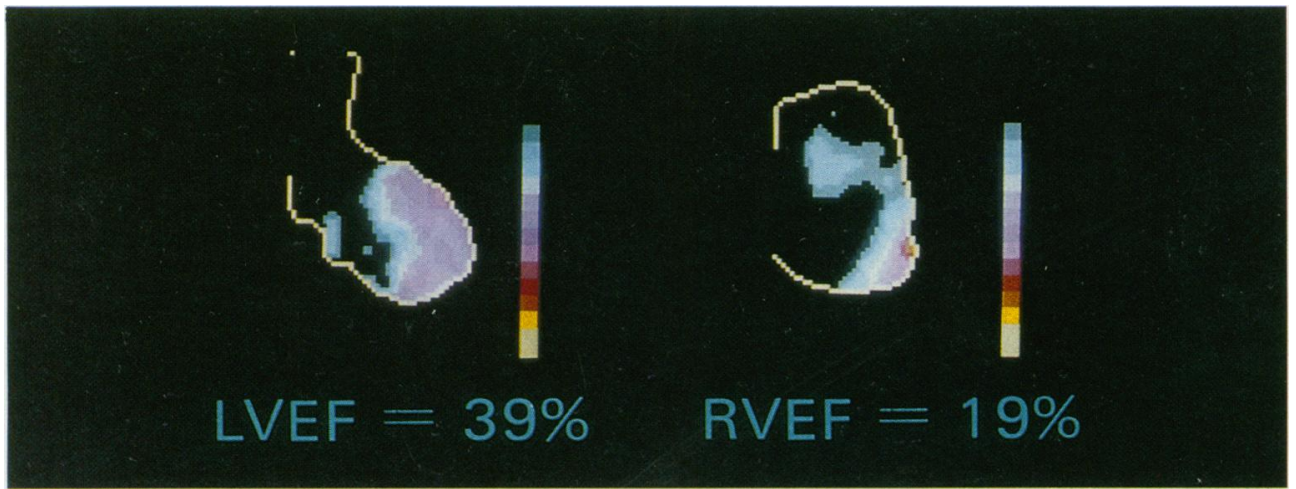

Fig 7 Right and left ventricular images in a patient with inferior myocardial infarction associated with hypokinesis of the right ventricular free wall (inferior border) and the inferior left ventricle. See fig 3 for colour scale.

the superior vena cava. The right ventricular area was significantly greater in the group with inferior infarction, suggesting right ventricular dilatation $(p<0.05)$. Both the number of right ventricular cycles available for analysis $(p<0.05)$, and, as a consequence of this, the right ventricular transit times $(p<0.01)$, were greater in the inferior infarction group. There were, however, no significant differences between the groups in left ventricular cycles and transit times. The right ventricular ejection fraction was lower in the inferior infarction group, but this failed to reach statistical significance when compared with the anterior infarction group. In contrast, the left ventricular ejection fraction was significantly lower in the group with anterior infarction $(p<0.05)$.

Regional abnormalities of both right and left ventricular function were common in both groups (table 3). However, abnormalities of regional right ventricular wall motion in the group with anterior infarction tended to involve the septal wall, whereas in the group with inferior infarction the free wall was predominantly involved. Regional abnormalities of the left ventricle affected the appropriate segment and were also dependent upon the site of the myocardial infarction. These abnormalities were present in all eight patients with abnormal left ventricular ejection fractions and also in eight patients with normal resting left ventricular ejection fractions.

\section{Discussion}

Although the clinicopathological syndrome of myocardial infarction has been known for at least a cen- tury, ${ }^{14}$ dominant right ventricular involvement was first described within the past twelve years. ${ }^{1}$ A study $\frac{c}{\infty}$ of 2000 consecutive necropsies found right ventricular infarction in $13.8 \%$, the majority being associ- $\infty$ ated with extension from a left ventricular infarction, but in $2.4 \%$ the infarction was confined to the right ventricle. ${ }^{15}$ Other investigators found that the right ventricle was affected only when there was transmural inferior left ventricular infarction ${ }^{16}$; Ratliff and Hacket found that the right ventricle $\mathbb{\Phi}$ was affected in $34 \%$ of such patients. ${ }^{17}$ Wade $\underset{F}{\Rightarrow}$ described 11 patients with right ventricular infarction all of whom had proximal occlusion of the right coronary artery. ${ }^{18}$ This is not surprising since the right ventricular free wall, in man, is exclusively supplied by the right coronary artery. ${ }^{3}$ It is now recognised, however, that free wall contraction contributes only part, and possibly a small part, of the total systolic volume change of the right ventricle. Contraction of the interventricular septum and the crista supraventricularis may be far more important than that of the free wall. ${ }^{8}$ Since the interventricular $ᄋ$ septum receives blood from the left anterior $D$ descending coronary artery, right ventricular dysfunction might occur not only in patients with infe- $N$ rior infarction but also in those with anterior of infarction.

In an early study Rigo et al showed that the ratio of right ventricular to left ventricular area after inferior infarction was higher than after anterior infarction, suggesting disproportionate dilatation of the right ventricle. ${ }^{4}$ Other investigators found that $\stackrel{?}{?}$ the right ventricular ejection fraction was depressed 0 in patients after inferior infarction but normal in patients after anterior infarction, with some individ- 
uals having values below the lower level of normal. ${ }^{56}$ Steele et al found that all patients on the first day after inferior infarction had impaired right ventricular function that appeared to recover rapidly, whereas after anterior infarction only one third of patients developed transient abnormalities. ${ }^{19} \mathrm{Mar}-$ mor et al found impaired right ventricular function in patients after both inferior and anterior infarction, however, in contrast with Steele's data; this persisted in the group with inferior infarction but not in the group with anterior infarction. ${ }^{7}$ In a prospective trial of 250 consecutive coronary care admissions, "predominant" right ventricular dysfunction was found in $\mathbf{4 3}$ and all of them had inferior infarction. ${ }^{20}$ However, since only patients with nearly normal left ventricular function were included the selection was biased against patients with anterior infarction which causes greater depression of left ventricular ejection fractions. ${ }^{719}$

Since the first description of clinical right ventricular infarction there has been extensive work on the clinical, ${ }^{1}$ electrocardiographic, ${ }^{21}$ and haemodynamic $^{22}$ diagnosis of right ventricular infarction and dysfunction. There is often a discrepancy between the diagnosis of right ventricular infarction, primarily a histopathological finding, and right ventricular dysfunction, a clinical and pathophysiological entity. Thus it seems apparent that while right ventricular free wall infarction is related to inferior infarction and right coronary artery disease, ${ }^{17}$ right ventricular dysfunction may occur independently of these features when it is associated with anterior infarction. ${ }^{718}$

We examined various variables of right and left ventricular function in a group of patients soon after infarction. Right ventricular ejection fraction was depressed in $55 \%$ of the patients and left ventricular ejection fraction in $40 \%$. These figures are similar to those obtained in other studies. ${ }^{457}$

Left ventricular dysfunction (ejection fraction $<50 \%$ ) was more common in the group with anterior infarction $(60 \%)$ than in the group with inferior infarction $(20 \%)$. Right ventricular area was significantly smaller and right ventricular transit significantly more rapid in the group with anterior infarction than in the group with inferior infarction, despite the fact that not only the right ventricular ejection fraction but also the number of patients in each group with impaired global and regional right ventricular abnormalities were similar. The differences between the groups cannot be attributed to difference in timing of the studies because the mean study day was the same in both groups. These data confirm that right ventricular dilatation is disproportionately increased in patients with inferior infarction compared with anterior infarction and is associated with impaired transit. This may explain why the haemodynamic changes suggestive of dominant right ventricular dysfunction occur almost exclusively after inferior infarction. ${ }^{20} 22$ In addition, as mentioned previously, left ventricular dysfunction is far more common in patients after anterior infarction, ${ }^{719}$ and therefore isolated right ventricular dysfunction is far less likely to occur in this group.

Figures 2 and 5 show the relations between left and right ventricular ejection fractions in both groups. In patients with anterior infarction there is an impressive linear relation between right and left ventricular function. There are two possible explanations: firstly, that a large anterior infarction causes greater left ventricular ejection dysfunction, involves more of the interventricular septum, and therefore causes greater disturbance in right ventricular function; or alternatively, that a large anterior infarction produces a greater reduction in left ventricular ejection fraction, a greater increase in left ventricular diastolic filling pressure, and hence an increase in pulmonary arterial pressures and right ventricular afterload. The occurrence of regional rather than diffuse septal abnormalities of the right ventricle after anterior infarction tends to favour the former explanation.

In the group with inferior infarction there was no such relation between right and left ventricular ejection fractions. This is as expected since involvement of the free wall of the right ventricle may occur in the absence of a large inferior infarction, ${ }^{16}$ and this was confirmed by the regional images. These data are similar to those of Marmor et al who also found a linear relation between right and left ventricular ejection fractions in patients with anterior infarction and no relation in those with inferior infarction. The equilibrium gated technique was used and they were less able to examine regional right ventricular performance, but right ventricular ejection fraction depression was related to the extent of septal involvement in anterior infarction. ${ }^{7}$

We studied only a small number of patients and thus our results must be interpreted with some care; however, there do appear to be significant differences between the two groups. The limitations of a static rather than mobile camera meant that only patients fit enough to be moved to the camera could be imaged. Thus while $85 \%$ of patients were imaged within one week of their myocardial infarction, imaging with a mobile gamma camera early after admission, that is, within 24 hours, might have produced different results. Steele et al initially imaged patients within 24 hours, ${ }^{19}$ and Marmor et al within 48 hours of the onset of chest pain. ${ }^{7}$ Since both of these studies suggested some improvement of right 
ventricular function with time, the present study may well underestimate the frequency of right ventricular dysfunction since no patient was imaged within two days of infarction. Development of mobile multicrystal cameras and single crystal cameras capable of performing first pass studies ${ }^{23}$ will allow assessment in the coronary care unit. To date only three patients have proceeded to coronary angiography. It is therefore not yet possible to comment on the relation between global and regional right ventricular dysfunction and coronary anatomy.

We used the right anterior oblique projection for these studies. This is the ideal projection for the assessment of the right ventricle since right atrial overlap is minimised. ${ }^{24}$ While it can be argued that the left anterior oblique projection provides the best separation of the right ventricular free wall and septal wall, this projection leads to maximal right atrial overlap of the right ventricle. Although the usefulness of regional wall motion images has been questioned, this study does suggest that information can be obtained on regional right ventricular dysfunction by this method.

These data confirm that right ventricular dysfunction is common in patients in the acute phase of myocardial infarction. They suggest an explanation for the predominance of patients with inferior infarction in studies of "dominant" right ventricular dysfunction. They also suggest that septal contribution to right ventricular contraction is far from negligible and they provide an explanation for the apparently minimal effects of isolated destruction of the right ventricular free wall in laboratory animals. ${ }^{2526}$ Because appropriate treatment for cardiogenic shock secondary to right ventricular dysfunction is most effective, ${ }^{27}$ the ability to assess non-invasively global and regional right ventricular function in patients after myocardial infarction may prove important in the management of these patients.

JLC is supported by the British Heart Foundation.

\section{References}

1 Cohn JN, Giuha NH, Broder MI, Limas CJ. Right ventricular infarction. Clinical and hemodynamic features. Am J Cardiol 1974;33:209-14.

2 Swan HJC, Ganz W, Forrester J, Marcus H, Diamond G, Chonette D. Catheterization of the heart in man with the use of a flow directed balloon-tipped catheter. N Engl J Med 1970;283:447-51.

3 Farrer-Brown G. Vascular pattern of myocardium of right ventricle of human heart. $\mathrm{Br}$ Heart $J$ 1968;30:679-86.
4 Rigo P, Murray M, Taylor DR, et al. Right ventricular dysfunction detected by gated scintiphotography in patients with acute inferior myocardial infarction. Circulation 1975;52:268-74.

5 Reduto LA, Berger HJ, Cohen LS, Gottschalk A, Zaret BL. Sequential radionuclide assessment of left and right ventricular performance after acute transmural myocardial infarction. Ann Intern Med 1978;89: 441-7.

6 Tobinick E, Schelbert HR, Henning H, et al. Right ventricular ejection fraction in patients with acute anterior and inferior myocardial infarction assessed by radionuclide angiography. Circulation 1978;57: 1078-84.

7 Marmor A, Geltman EM, Biello DR, Sobel BE, Siegel $B A$, Roberts R. Functional response of the right ventricle to myocardial infarction: dependence on the site of left ventricular infarction. Circulation 1981;64: 1005-11.

8 James TN. Anatomy of the crista supraventricularis: its importance for understanding right ventricular function, right ventricular infarction and related conditions. J Am Coll Cardiol 1985;6:1083-95.

9 Dymond DS, Jarritt PH, Britton KE, Spurrell RAJ. Detection of postinfarction left ventricular aneurysms by first pass radionuclide ventriculography using a multicrystal gamma camera. $\mathrm{Br}$ Heart $J$ 1979;41:68-78.

10 Dymond DS, Elliot A, Stone D, Hendrix G, Spurrell $R$. Factors that affect the reproducibility of left ventricular function from first-pass radionuclide angiograms. Circulation 1982;65:311-22.

11 Dymond DS, Grenier RP, Schmidt DH. Right ventricular ejection fraction from first-pass radionuclide angiograms: comparison with right ventriculography [Abstract]. J Nucl Med 1981;22:P23.

12 Dymond DS, Foster C, Grenier RP, Carpenter J, Schmidt DH. Peak exercise imaging for the detection of left ventricular function abnormalities in coronary artery disease. Am J Cardiol 1984;53:1532-7.

13 Caplin JL, Dymond DS, Maltz MB, O'Keefe JC, Flatman WD, Spurrell RAJ. Right ventricular function at rest and exercise in normals [Abstract]. Clin Sci 1985;68 (suppl 11):44P.

14 Lie JT. Centenary of the first correct antemortem diagnosis of coronary thrombosis by Adam Hamer (1818-78): English translation of the original report. Am J Cardiol 1978;42:849-52.

15 Wartmann WB, Hellerstein HF. The incidence of heart disease in 2000 consecutive autopsies. Ann Intern Med 1948;28:41-54.

16 Isner JM, Roberts WC. Right ventricular infarction complicating left ventricular infarction secondary to coronary heart disease. Am J. Cardiol 1978;42: 885-94.

17 Ratliff NB, Hacket DB. Combined right and left ventricular infarction. Pathogenesis and clinicopathological correlation. Am J Cardiol 1980;45: 217-21.

18 Wade WG. The pathogenesis of infarction of the right ventricle. Br Heart J 1959;21:545-54.

19 Steele P, Kirch D, Ellis J, Vogel R, Battock D. Prompt 
return to normal of depressed right ventricular ejection fraction in acute inferior infarction. $\mathrm{Br}$ Heart $J$ 1977;39:1319-23.

20 Shah PK, Maddahi J, Berman DS, Pichler M, Swan HJC. Scintigraphically detected predominant right ventricular dysfunction in acute myocardial infarction: clinical hemodynamic correlates and implication for therapy and prognosis. J Am Coll Cardiol 1985;6:1264-72.

21 Erhardt LR, Sjögren A, Wahlberg J. Single right-sided precordial lead in the diagnosis of right ventricular involvement in inferior myocardial infarction. $\mathrm{Am}$ Heart J 1976;91:571-6.

22 Lopez-Sendon J, Coma-Canella I, Gamello C. Sensitivity and specificity of hemodynamic criteria in the diagnosis of acute right ventricular infarction. Circulation 1981;64:515-25.

23 Flatman WD, Dymond DS, O'Keefe J, Caplin J, Dyke
LJ. First-pass measurement of global and regional left ventricular function using a digital single crystal camera: comparison with a multicrystal camera. Nuklearmedizin 1984;21:182-4.

24 Ferlinz J. Measurement of right ventricular volumes in man from single-plane cineangiograms. Am Heart J 1977;94:87-90.

25 Starr I, Jeffers WA, Medde RH. The absence of conspicuous increments in venous pressure after severe damage to the right ventricle of the dog, with a discussion of the relationship between congestive cardiac failure and heart disease. Am Heart $J$ 1943;26:291-301.

26 Guiha NH, Limas CJ, Cohn JN. Predominant right ventricular dysfunction after right ventricular destruction in the dog. Am J Cardiol 1974;33:254-8.

27 Cohn JN. Right ventricular infarction revisited. $\mathrm{Am} \mathrm{J}$ Cardiol 1979;43:666-8. 